\title{
Complete sequence of heterogenous-composition mitochondrial genome (Brassica napus) and its exogenous source
}

\author{
Juan Wang ${ }^{1 \dagger}$, Jinjin Jiang ${ }^{1 \dagger}$, Xiaoming $\mathrm{Li}^{1}$, Aimin $\mathrm{Li}^{2}$, Yongtai Zhang ${ }^{2}$, Rongzhan Guan ${ }^{3}$ and Youping Wang ${ }^{1 *}$
}

\begin{abstract}
Background: Unlike maternal inheritance of mitochondria in sexual reproduction, somatic hybrids follow no obvious pattern. The introgressed segment orf138 from the mitochondrial genome of radish (Raphanus sativus) to its counterpart in rapeseed (Brassica napus) demonstrates that this inheritance mode derives from the cytoplasm of both parents. Sequencing of the complete mitochondrial genome of five species from Brassica family allowed the prediction of other extraneous sources of the cybrids from the radish parent, and the determination of their mitochondrial rearrangement.
\end{abstract}

Results: We obtained the complete mitochondrial genome of Ogura-cms-cybrid (oguC) rapeseed. To date, this is the first time that a heterogeneously composed mitochondrial genome was sequenced. The 258,473 bp master circle constituted of 33 protein-coding genes, 3 rRNA sequences, and 23 tRNA sequences. This mitotype noticeably holds two copies of atp9 and is devoid of cox2-2. Relative to nap mitochondrial genome, 40 point mutations were scattered in the 23 protein-coding genes. atp6 even has an abnormal start locus whereas tatC has an abnormal end locus. The rearrangement of the 22 syntenic regions that comprised $80.11 \%$ of the genome was influenced by short repeats. A pair of large repeats (9731 bp) was responsible for the multipartite structure. Nine unique regions were detected when compared with other published Brassica mitochondrial genome sequences. We also found six homologous chloroplast segments (Brassica napus).

Conclusions: The mitochondrial genome of oguC is quite divergent from nap and pol, which are more similar with each other. We analyzed the unique regions of every genome of the Brassica family, and found that very few segments were specific for these six mitotypes, especially cam, jun, and ole, which have no specific segments at all. Therefore, we conclude that the most specific regions of oguC possibly came from radish. Compared with the chloroplast genome, six identical regions were found in the seven mitochondrial genomes, which show that the Brassica family has a stable chloroplast-derived source.

\section{Background}

The major function of the mitochondria (mt), as a semiautonomous organelle, in plant growth and development is to provide energy through oxidative phosphorylation [1]. In different to the small $\mathrm{mt}$ genome of animals ( 16 kb), plants have longer mtDNA ranging from $200 \mathrm{~kb}$ to $2000 \mathrm{~kb}[2,3]$. To date, several $\mathrm{mt}$ genomes from fertile and sterile plant species have been sequenced, including

\footnotetext{
* Correspondence: wangyp@yzu.edu.cn

${ }^{+}$Equal contributors

'Jiangsu Provincial Key Laboratory of Crop Genetics and Physiology,

Yangzhou University, Yangzhou 225009, China

Full list of author information is available at the end of the article
}

Arabidopsis thaliana [4], Oryza sativa [5-7], Beta vulgaris [8,9], Zea mays [10,11], Nicotiana tabacum [12], Triticum aestivum [13,14], and five species from the Brassica genus, i.e., B. napus (pol, nap), B. rapa (cam), B. oleracea (ole), B. juncea (jun), and B. carinata (car) [15-17]. The sequencing results indicated that apart from ribosomal protein genes, protein-coding genes are also relatively conserved both in nucleotide sequence and in number. However, the non-coding sequences are quite inconsistent among species, and even within the same species. The presence of large and short repeats is responsible for the dynamic multipartite structures, reorganization, and recombination [17].

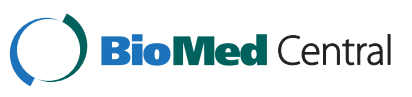


In higher plants, mitochondrial inheritance usually follows the maternal origin during sexual hybridization. However, much more complicated modes are detected in somatic hybridization, wherein $\mathrm{mt}$ genome inheritance is derived from either or both biparents [18]. In the latter pattern, part of the $\mathrm{mt}$ genome, including cytoplasmic male sterility (CMS) genes, can be transferred from the donor parent to the receptor parent, and the introgressed segment experiences extensive rearrangement and recombination with the mtDNA of the receptor one. Orf138, originally identified in radish, was transferred successfully to various species, including Arabidopsis, B. napus, and B. oleracea by somatic hybridization [19-25].

CMS genes have a defect in the production of functional pollen. Generally, genes associated with CMS genes are located in the periphery of certain known mitochondrial genes and are cotranscribed with them [26]. T-urf13 (orf115) was the first identified aberrant gene in the Texas (T)-cytoplasm of maize, which encodes a $13 \mathrm{kDa}$ membrane-spanning polypeptide that depolarizes the mitochondria and leads to cell death [2729]. In the BT (Boro II)-type CMS line of rice, orf79 was cotranscribed with the atp 6 gene forming a $2.0 \mathrm{~kb}$ transcript [30]. The expressed protein contains a predicted transmembrane domain [31].

In the Brassica genus, the complete mt genomes of five species are sequenced, coupled with the basic feature of published CMS genes, which allows the detection of the extraneous source from donor parent (radish) of somatic hybrids.

\section{Results}

Genome size and nucleotide sequence in the genic region The oguC mt genome was assembled into a 258,473 bp master circle with $45.21 \% \mathrm{G}+\mathrm{C}$ content (Figure 1). It encodes 33 proteins, three ribosomal RNA sequences (18s, 26s, and 5s), and 23 tRNA sequences, which account for $25.42 \%$ of the genome in total. Of these 33 protein-coding genes, two were identical copies of atp 9 and the cox2-2 gene were absent. Taken mtDNA from nap CMS as control, two genes were detected to change

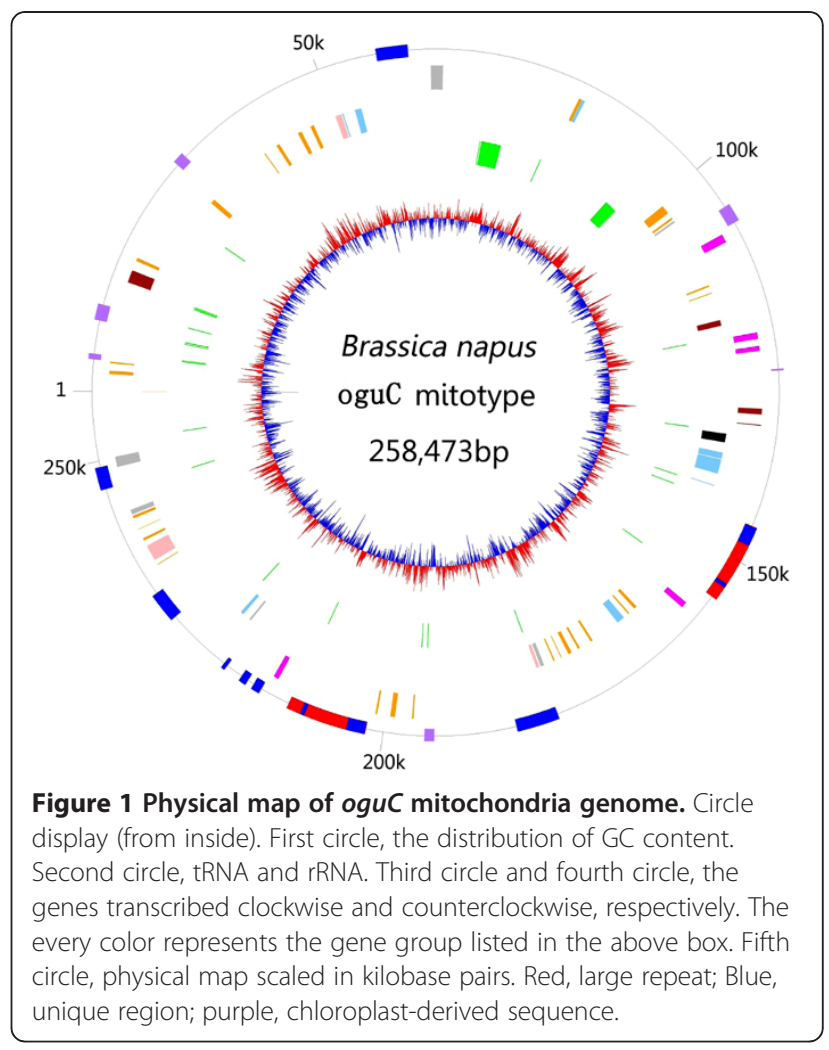

the coding length. One of them is tat $C$, whose several continuous mutations were observed in the 3 -end and the stop codon was extended 27bp away (Figure 2A). Similar to the change in tatC, an additional $498 \mathrm{bp}$ (including start codon) was placed in the 5/-end of atp6, whose nucleotide was completely identical to the one from radish (Figure 2B). Most of the other proteincoding genes were conserved in length, but the point mutation occurred extensively, where 40 single nucleotide polymorphisms (SNPs) were identified scattered among the 23 genes when compared to nap. Of the 40 SNPs, 13 were synonymous and 27 were nonsynonymous (Table 1). Most of the variations were transitions. Compared with their counterparts in Raphanus sativus, cox1, rps12, and atp 8 were also the same in terms of amino acid and nucleotide sequence except for atp6. $\mathrm{ccm} C$ had 10 nucleotide substitutions, where

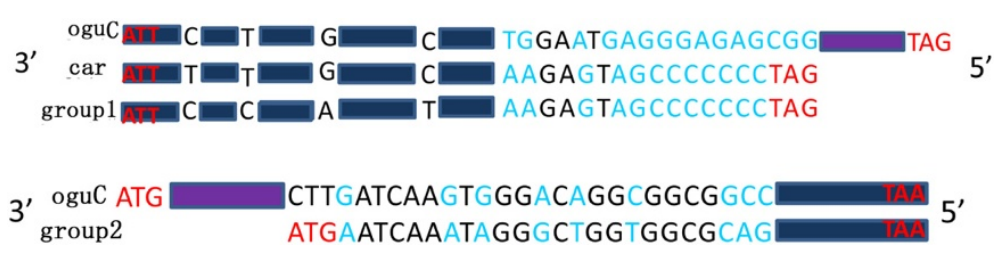

Figure 2 The comparison of nucleotide sequence of $\operatorname{tatC}(\mathbf{A})$ and atp6 (B) from Brassica family. Purple box means the extension segments in oguC, black box represents the identical segments rooted in the mtDNA of Brassica family. Group 1 contains ole, cam, pol, jun and nap. Group 2 represents ole, cam, pol, jun, nap and car. 
Table 1 SNP in protein-coding genes of mtDNA between oguC and nap

\begin{tabular}{|c|c|c|c|c|}
\hline Gene & Nucleic acid ${ }^{a}$ & Amimo acid $^{b}$ & Mutation type $^{c}$ & SNP type \\
\hline nadl & $571 \mathrm{C}-\mathrm{T}$ & $191 \mathrm{L-F}$ & $\mathrm{N}$ & transition \\
\hline nad2 & $367 \mathrm{~T}-\mathrm{C}$ & $123 C-R$ & $\mathrm{~N}$ & transition \\
\hline nad3 & $265 \mathrm{~T}-\mathrm{C}$ & & $S$ & transition \\
\hline \multirow[t]{2}{*}{ nad4 } & $77 \mathrm{C}-\mathrm{T}$ & $26 \mathrm{P}-\mathrm{L}$ & $\mathrm{N}$ & transition \\
\hline & 1205 C-T & $402 \mathrm{P}-\mathrm{L}$ & $\mathrm{N}$ & transition \\
\hline nad7 & 1079 T-C & 360 F-S & $\mathrm{N}$ & transition \\
\hline \multirow[t]{3}{*}{$\cos 1^{*}$} & 109 C-T & & S & transition \\
\hline & $111 \mathrm{~T}-\mathrm{A}$ & & $S$ & transversion \\
\hline & 786 T-G & & S & transversion \\
\hline $\cos 2-1$ & 379 T-C & $127 \mathrm{~W}-\mathrm{R}$ & $\mathrm{N}$ & transition \\
\hline $\mathrm{ccmB}$ & 353 G-A & & $\mathrm{N}$ & transition \\
\hline \multirow[t]{7}{*}{$\mathrm{ccmC}^{* *}$} & $126 \mathrm{~A}-\mathrm{G}$ & & $\mathrm{S}$ & transition \\
\hline & $155 \mathrm{G}-\mathrm{A}$ & $52 \mathrm{R}-\mathrm{H}$ & $\mathrm{N}$ & transition \\
\hline & 338 G-A & $113 \mathrm{R}-\mathrm{K}$ & $\mathrm{N}$ & transition \\
\hline & $351 \mathrm{G}-\mathrm{A}$ & & $S$ & transition \\
\hline & 476 C-A & & $S$ & transversion \\
\hline & 533 G-A & $178 \mathrm{G}-\mathrm{A}$ & $\mathrm{N}$ & transition \\
\hline & $551 \mathrm{G}-\mathrm{A}$ & 184 G-D & $\mathrm{N}$ & transition \\
\hline $\mathrm{ccmFC}$ & $283 \mathrm{G}-\mathrm{A}$ & $95 \mathrm{E}-\mathrm{K}$ & $\mathrm{N}$ & transition \\
\hline \multirow[t]{2}{*}{ ccmFN1 } & 361 T-A & $121 \mathrm{~F}-\mathrm{I}$ & $\mathrm{N}$ & transversion \\
\hline & $1000 \mathrm{C}-\mathrm{T}$ & $334 \mathrm{~L}-\mathrm{F}$ & $\mathrm{N}$ & transition \\
\hline $\mathrm{ccmFN2}$ & 380 C-T & $127 \mathrm{~L}-\mathrm{S}$ & $\mathrm{N}$ & trnasition \\
\hline atp1 & 987 T-C & & $S$ & transition \\
\hline atp4 & 176 C-T & $59 \mathrm{~A}-\mathrm{V}$ & $\mathrm{N}$ & transition \\
\hline \multirow[t]{2}{*}{ atp8* } & $370 \mathrm{~A}-\mathrm{C}$ & $124 \mathrm{~L}-1$ & $\mathrm{~N}$ & transversion \\
\hline & $448 \mathrm{~T}-\mathrm{C}$ & $150 \mathrm{~A}-\mathrm{V}$ & $\mathrm{N}$ & transition \\
\hline atp9 & $64 \mathrm{~A}-\mathrm{G}$ & $22 \mathrm{I}-\mathrm{V}$ & $\mathrm{N}$ & transition \\
\hline \multirow[t]{2}{*}{ rps3 } & $1254 \mathrm{~A}-\mathrm{C}$ & & $S$ & transversion \\
\hline & $1320 \mathrm{~A}-\mathrm{C}$ & & $S$ & transversion \\
\hline \multirow[t]{2}{*}{ rps4 } & 189 T-G & & $S$ & transversion \\
\hline & 776 C-T & 259 S-F & $\mathrm{N}$ & transition \\
\hline \multirow[t]{3}{*}{$\operatorname{rps} 12^{*}$} & $12 \mathrm{~T}-\mathrm{G}$ & $4 \mathrm{~F}-\mathrm{L}$ & $\mathrm{N}$ & transversion \\
\hline & 336 A-C & 112 R-S & $\mathrm{N}$ & transversion \\
\hline & $345 \mathrm{~A}-\mathrm{C}$ & & $S$ & transversion \\
\hline \multirow[t]{3}{*}{$r p / 2$} & $464 \mathrm{G}-\mathrm{A}$ & 155 G-D & $\mathrm{N}$ & transition \\
\hline & 840 C-T & & $S$ & transition \\
\hline & 1004 C-T & 335 S-L & $\mathrm{N}$ & transition \\
\hline$r p / 5$ & $515 \mathrm{~T}-\mathrm{C}$ & $172 \mathrm{L-P}$ & $\mathrm{N}$ & transition \\
\hline rp/16 & 506 C-T & 169 P-L & $\mathrm{N}$ & transition \\
\hline
\end{tabular}

a Location of base mutation, ${ }^{\mathrm{b}}$ Location and switch of amino acid mutation,

' S,Synonymous; N, Non-synonymous.

* Nucleotide sequence of genes identical to Raphanus sativus ** Two SNPs

when compared to Raphanus sativus.

4. were non-synonymous. Using $R$. sativus as the control, only two SNPs were detected: one differs by a synonymous mutation in position 126, similar to the alignment of nap; the other was a $\mathrm{G}$ to A mutation in position 146, which caused a Thr to Gly switch. Among the 34 protein-coding genes in pol, 31 have an identical copy in nap and only 3 genes showed locus polymorphism [15]. Consequently, many variations in $o g u C$ may be associated with its background of somatic hybridization and complicated evolution.

\section{Reconstruction of the nap-CMS cybrid mitochondrial genome}

The syntenic regions of $o g u C$ and nap were analyzed using a bl2seq algorithm. A total of 22 segments ranging from 1393 bp to 30232 bp possessed at least 95\% similarity and at least $1 \mathrm{~kb}$ in size, which were responsible for $80.11 \%$ and $92.78 \%$ of these two mitotype genomes, respectively. The majority of the syntenic regions contained 99\% similarity except S10 (97\%), S16 (98\%), S18 (96\%), S20 (96\%), and S21 (95\%). The direction of 10 regions was identical, but that of the other 12 was the opposite (Figure 3). Estimating the minimum recombination events that occurred to account for the restructuring of the two mitotypes was difficult because of the many syntenic regions.

\section{Reorganization of the mitochondrial genome}

The large and short repeats were analyzed. The circle molecule had a pair of large repeat sequences (9731 bp) and only a trnY gene was included. It is about four times the length of equivalent from nap (2427bp), but no sequence similarity was found between them (Figure 1). One of the two direct repeats in $o g u C$ occupied the nonsyntenic region between S7 and S14 and another one extended from the end of S13 to the start of S18 (Figure 4). The presence of large repeats is believed to be associated with the formation of multipartite structure $[15,32]$, which are isomeric forms that consist of the master circle and two smaller subgenomic circles (56610 bp and 201863 bp) via intramolecular homologous recombination in $\mathrm{oguC}$ (Figure 4). The coexistence phenomenon of various molecular forms was extensively predicted in many species sequenced that were verified through direct observation using electron microscopy in tobacco [33].

Apart from the large repeats, the $\mathrm{mt}$ genome of higher plants also distributes massive short repeats [25]. We identified 123 repeats $(30-500 \mathrm{bp}$, similarity $\geq 90 \%$ ), including both direct and inverted repeats, that were responsible for $6.54 \%$ of the genome. The short repeats contributed to genome reorganization and arrangements, although the frequency of these events was not as high $[34,35]$. We assayed reorganization relationship of some syntenic regions and found that two short repeats were closely related to the rearrangement of five syntenic domains, as elaborated on Figure 5. S1, S4, and 
S9 were originally located adjacent to each other in nap. S9 was on the opposite direction and only $610 \mathrm{bp}$ was present between S1 and S4. However, because of the reorganization caused by the repeating R1 (310 bp), S4 and S1 transposed with each other that made the gap between them disappeared. On the other hand, S9 was separated to thousands of base pairs away and shifted the orientation. Another was the combined fragments of S8 and S19, which was divided by increasing the copies of R2 (232 bp) in oguC. Similar rearrangement relationship was also discovered in other mtDNA [15,17].

\section{Unique region of the genome}

We investigated the CMS-specific mitochondrial regions by comparing it with the other six entire mitochondrial genome sequences of Brassica species (Figure 6). Up to 11 unique regions, which constitute $8.89 \%$ of the genome, were assayed (Table 2). U1 and U2 had two identical copies that were included in the large repeats. U3 almost fully occupied the gap between S5 and S23, similar to U7, which possessed the non-syntenic region between S11 and S16. U3, which included orf138, must have come from the radish mtDNA. The speculation was proved again by the fact that this segment was almost $100 \%$ identical to the orf138-included region from $R$. sativus (accession number: Z18896). Atp6 was equal to that from radish, with first 422 bp contained in the end of U7. A domain composed of U7 plus the next 862 bp of atp 6 was also possibly from radish because a part of its sequence is found in radish (accession number: M24672). The other CMS-specific regions were included in the partial region of the non-syntenic domains. Analyzing those specific regions using Blastn searches against the NCBI database, with sizes ranging from $2 \%$ in U1 to $100 \%$ in U5, were aligned with the mtDNA of Arabidopsis thaliana. For the blast and non-blast region from specific region, we speculated that they were either the transfer of nuclear counterpart from one of the biparents or originated from the mtDNA of radish, but the latter hypothesis was more reasonable. More empirical proofs are needed to demonstrate this.

\section{Homology with rapeseed chloroplast genome}

Exogenous segments of the intergenic spacer are derived from the chloroplast genome and these sequences migrate and integrate into the $\mathrm{mt}$ genome $[14,36]$. Thus, we analyzed the homology between oguC mtDNA and rapeseed (B. napus) chloroplast genome. Six homologous segments with more than $95 \%$ identity were found in this genome (Table 3). The six segments ranged from $178 \mathrm{bp}$ to $2196 \mathrm{bp}$, and accounted for $2.88 \%$ of the total $\mathrm{mt}$ genome. All of the sequences were located in the syntenic region.

\section{ORFs and predicted CMS-related chimeric ORF in this genome}

We detected 39 ORFs in this genome, with the shortest size equal to $303 \mathrm{bp}$, which summed to $7.41 \%$ of the mitotype. Of the 39 ORFs, 23 (similarity $\geq 99 \%$ ) were shared in one or more Brassica genomes, which were remotely related to CMS. However, they are likely functional genes as these later-discovered genes $c c m$, orf 25 (atp4), and orfB (atp8) [37,38]. Of the remaining 16 unique ORFs in the oguC mitochondrial genome, 8 ORFs were totally not matched and 8 were partly identical to those present in the other six mitotypes. Five, including orf138, which is the oguC-related CMS gene,

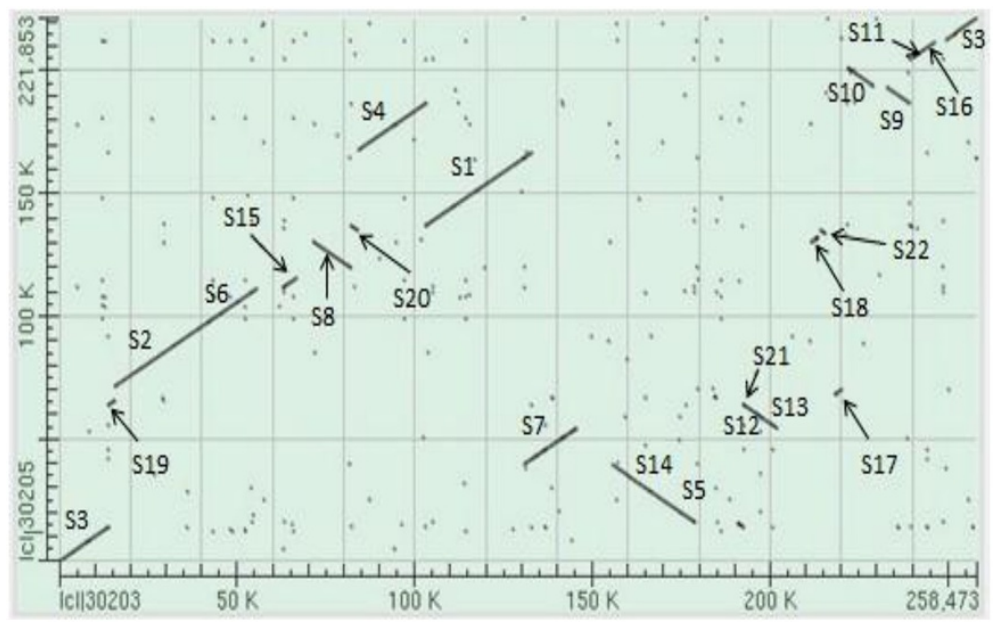

Figure 3 Syntenic regions of oguC and nap mitotype genome. S1-S24 refer to the syntenic regions (similarity $\geq 95 \%$, length $\geq 1 \mathrm{~kb}$ ). Horizontal axis and vertical axis mean the whole genome nucleotide sequence of oguC and nap, respectively. 


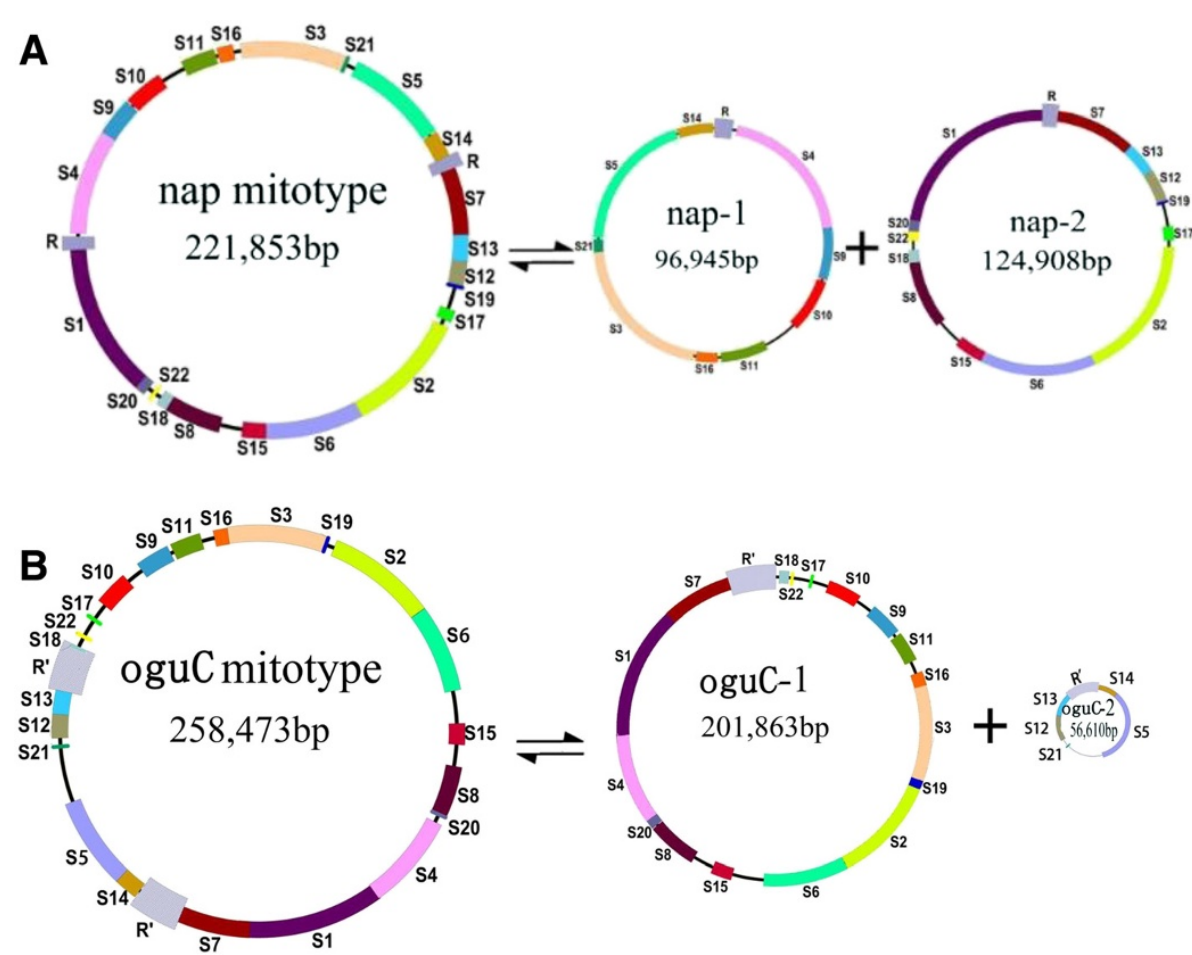

Figure 4 The tripartite structure of the two mitotypes. S1-S22 represent the syntenic region as illustrated in Figure 3. A, oguC mitotype; B, nap mitotype. $R$ and $R^{\prime}$, large repeat.

out of eight non-matched ORFs were completely or partially situated in the unique regions (Table 2). Three common ORFs and three unique ORFs were located in the cp-derived domains (Table 3). Among them, orf210 and orf344-1 were highly similar to 2 segments of the beta subunit of RNA polymerase, which were wholly situated in the chloroplast genome with a length of 1072 amino acids. When the intact nucleotide sequence of beta subunit of RNA polymerase was aligned with $o g u C$

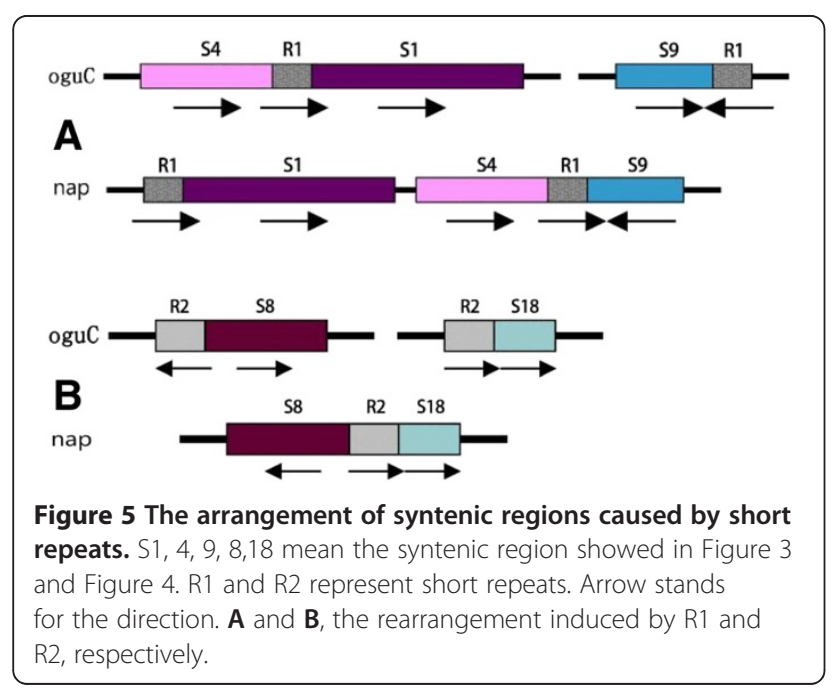

mtDNA, H1 was found to be a truncated RNA polymerase beta subunit with $97 \%$ similarity. Some point mutations and indels resulted in the production of these two ORFs. Similar to orf344-1, a truncated ribulose-1, 5bisphosphate carboxylase/oxygenase large subunit $(r b c L)$ gene from cp genome evolved into orf313. Based on the three features of CMS related genes, namely, unique to the given mitotype, membrane-spanning domains and near to the functional genes [26,39], orf138, which encodes a $19 \mathrm{kDa}$ transmembrane protein that showed toxicity to bacterial growth, can be suppressed by the nuclear Rfo locus [40-43].

\section{Discussion}

We obtained the complete mt genome of the oguC devoid of cox2-2 and increased copy of atp9. Cox2-1 and cox $2-2$ were distributed in the start region of S7 and the end region of S1 in nap mitotype (Figure 7), respectively. However, as the rearrangement and reconstruction of $\mathrm{mt}$ genome, S1 and S7 were translocated adjacent to each other in oguC. In addition, the first $2425 \mathrm{bp}$ and last $2425 \mathrm{bp}$ domains of S7, in which the cox gene was included, were incorporated into one superposition. Consequently, the cox2-1 gene was saved whereas the cox2-2 was lost. This phenomenon was also observed in car and ole mitotypes [17]. For the atp9, one was located 


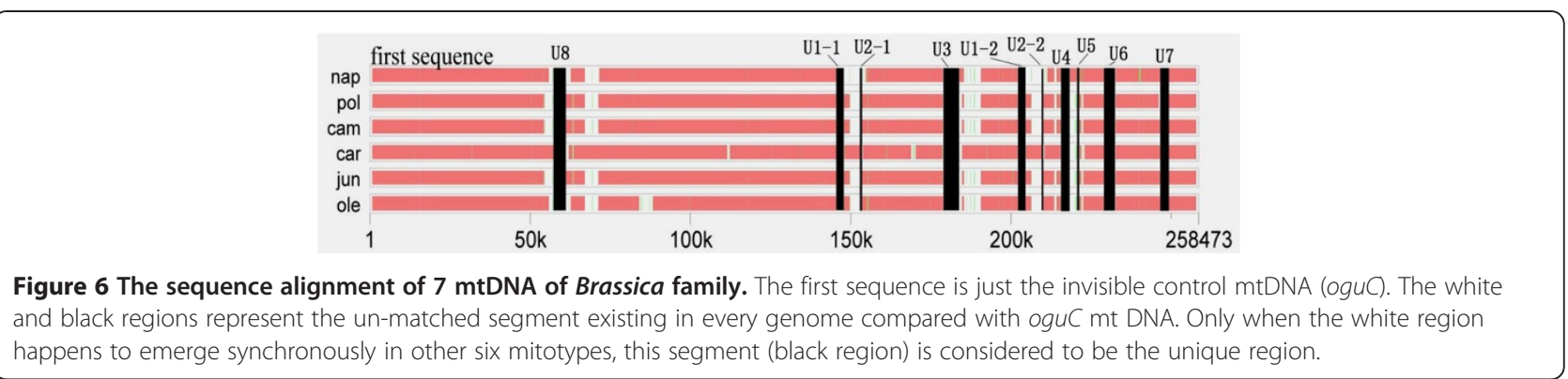

in the syntenic region, which is in itself, and the other one was in the non-syntenic region. Compared to the NCBI data with a 767 bp segment, including the redundant atp9 with its perimeter zone, we found that this segment was almost 100\% identical to the corresponding section in the $940 \mathrm{bp}$ domain from the mitochondrial atp 9 pseudogene of F0-F1 ATPase proteolipid from $R$. sativus (accession number: X69320). The complete 940 bp segment from radish was likely broken into two parts; one with atp 9 included was fused into the reconstructed mitochondria during the rearrangement and reorganization that resulted from the collision of the cytoplasm of two cells, and the other one was lost. Additionally, tatC and atp6 were also reasonably speculated that they were fused from radish based on the additive length absent from the other 6 lines of Brassica family while completely identical to the counterpart of radish (Figure 2). However, although cox1, rps12, atp8 and $\mathrm{ccm} C$ share completely or partly same nucleotide sequence between $o g u C$ and radish (Table 1), we still can't make sure whether they were invaded from radish or not only by the SNPs analysis.

When nap mtDNA was taken as the control, 22 syntenic regions were detected in total. Estimating the number of recombination events was difficult because of the many syntenic regions. However, relative to two more

Table 2 Unique region found in oguC

\begin{tabular}{lcccc}
\hline No. & Length & Fine location & Remark & ORF included \\
\hline U1-1 & 2220 & $145578-147797$ & $\begin{array}{c}\text { included in the } \\
\text { large repeats }\end{array}$ & \\
\cline { 1 - 3 } U1-2 & 2220 & $202186-204405$ & & \\
\hline U2-1 & 469 & $153028-153496$ & & \\
\hline U2-2 & 469 & $209635-210104$ & & orf138 \\
\hline U3 & 5130 & $178771-183898$ & *S5-S23 & orf130 \\
\hline U4 & 1052 & $215584-216635$ & S22-S17 & \\
\hline U5 & 445 & $220503-220947$ & S17-S10 & \\
\hline U6 & 3572 & $229073-232643$ & S10-S9 & \\
\hline U7 & 2700 & $246585-249284$ & * S11-S16 & \\
\hline U8 & 3828 & $57304-61131$ & S6-S15 & orf122, orf102-1 \\
\hline U9 & 879 & $217471-218349$ & S22-S17 & part of orf101-4 \\
\hline * Totally occupy the spacer between two syntenic regions. &
\end{tabular}

similar mitotypes ( $p o l$ and nap) that have 13 syntenic region with the same analysis criterion (length $\geq 1000 \mathrm{bp}$, similarity $\geq 95 \%$ ) [15], it showed complex reconstruction. oguC mitotype must have undergone complicated changes and evolutionary events when the cytoplasm of two cells contacted each other.

The large repeat ( $\left.\mathrm{R}^{\prime}\right)$ in $\operatorname{og}_{u} \mathrm{C}$ was longer than others, except for R1, which mediates the homologous recombination with another two repeats, $\mathrm{R}$ and $\mathrm{R} 2$ in ole. The 5109 bp segment of R' showed 99\% similarity with R3 in car. Interestingly, except for ole, the six mt mitotypes contained only one large repeat, four of which contained the same large repeat, $\mathrm{R}$ (Table 4).

Using one genome of the seven mitotypes as the control to find the unique regions for every mitotype, the percentage ranged from $0 \%$ in three mitotypes (cam, jun, and ole) to $8.60 \%$ in oguC. Both nap and car contained three shorter specific segments constituting $0.74 \%$ and $1.57 \%$ of these two genomes, respectively. A $620 \mathrm{bp}$ unique segment located in pol contributed $0.28 \%$ to its total genome. In terms of the percentage, at least $7 \%$ of the exogenous sequences from radish mtDNA coexist with the oguC mtDNA (Table 4). When searched against the NCBI databases using those specific segments, similar alignments to that of oguC were obtained, some of which resembled those in Arabidopsis thaliana.

We also predicted the cp-derived sequence, which was intriguing because the seven mitotypes were blasted for the identical six segments with identities more than 95\% (Table 4). However, because of the large copy of R1, five cp-derived segments had two copies in ole. From

Table 3 Homologous segments to chloroplast of rapeseed found in oguC mitotype

\begin{tabular}{lcccc}
\hline No. & Fine location & Length & Identity & ORFs included \\
\hline $\mathrm{H} 1$ & $105622-107817$ & 2196 & $97 \%$ & orf210, orf344-1 \\
\hline $\mathrm{H} 2$ & $8547-10426$ & 1880 & $97 \%$ & orf100-2 \\
\hline $\mathrm{H} 3$ & $29583-30944$ & 1362 & $96 \%$ & orf313 \\
\hline $\mathrm{H} 4$ & $193870-195028$ & 1159 & $99 \%$ & orf257 \\
\hline $\mathrm{H} 5$ & $3828-4500$ & 673 & $96 \%$ & orf170 \\
\hline $\mathrm{H} 6$ & $126258-126435$ & 178 & $98 \%$ & \\
\hline
\end{tabular}




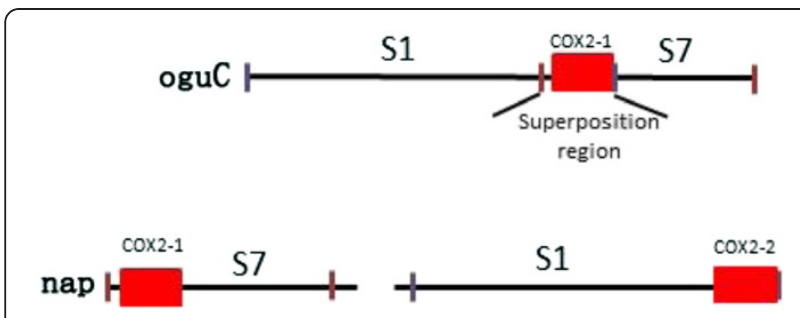

Figure 7 The position of cox gene in oguC and nap. S1 and S7 stand for the syntenic region as showed in Figure 2. Red box represents the cox gene.

the cp-derived data, we found that Brassica species have stable sources of chloroplast sequence.

\section{Conclusions}

This study finished mtDNA sequencing of a Ogura-cmscybrid $(o g u C)$, which derived from somatic fusion between Brassica napus and sterile radish. By contrast to one or more of six other Brassica lines, we reasonably speculated that tatC gene and 2 unique regions, U3 and U7, must be introgressed from radish. In addition, the rearrangement mediated by large and short repeats between these two parental mtDNAs extensively existed. With regard to the evolution of this integrated CMS mtDNA, more data need to be known.

\section{Methods}

Plant material and mitochondrial genome extraction

Seed of Brassica napus (ogu-CMS cybrid, oguC) was kindly provided by Norddeutsche Pflanzenzucht, HansGeorg Lembke KG (Germany). The etiolated one-week- old Brassica napus seedlings were prepared; the mitochondria and mtDNA extraction were performed following previously published methods [15]. To satisfy the requirements for 454 sequences, the minimum criterion for sample concentration was $50 \mathrm{ng} / \mu \mathrm{l}$ and total amount was equal to at least $20 \mu \mathrm{g}$.

\section{Genome sequencing}

A shotgun library that includes short and long paired end libraries were constructed simultaneously, which was followed by emulsion-based clonal amplification (emPCR) for DNA library bead enrichment. Finally, a genome sequencer FLX operation was conducted and the system output was derived. The contigs were joined by PCR sequencing. For the oguC genome, high quality read number, high quality bases, average read length, and sequencing depth were 8387, 3,913,351 bp, $469.3 \mathrm{bp}$, 15.2X, respectively. For SNP analysis and unique regions in $o g u C$ resequence was done.

\section{Genome analysis}

The genes scattered in this genome were annotated using the Blast service of NCBI. tRNAscan [44] and ORF finder (http://www.ncbi.nlm.nih.gov/gorf/gorf.html) were used to identify the tRNA sequences and potential ORFs, respectively. The unique regions of seven genomes were dug out with MultiPipMaker [45]. BlastN was used to discover large repeats. Short repeats were detected using commercial software developed by Shanghai Majorbio Bio-pharm Biotechnology Company (China). The accession numbers of the mtDNA are listed in Table 4.

Table 4 The composition of mitochondrial genomes of 7 mitotypes from Brassica family*

\begin{tabular}{|c|c|c|c|c|c|c|c|c|c|c|}
\hline \multicolumn{2}{|r|}{ Feature } & oguC & nap & pol & cam & car & jun & ole & & \\
\hline \multicolumn{2}{|c|}{ Accession number } & - & AP006444 & FR715249 & JF920285 & JF920287 & JF920288 & JF920286 & & \\
\hline \multicolumn{2}{|c|}{ Genome size (bp) } & 258473 & 221853 & 223412 & 219747 & 232241 & 219766 & 360271 & & \\
\hline \multicolumn{2}{|r|}{ GC\% } & 45.21 & 45.22 & 45.19 & 45.24 & 45.33 & 45.24 & 45.20 & & \\
\hline \multirow[t]{5}{*}{ Gene No. } & Protein-coding genes & 33 & 35 & 34 & 34 & 33 & 34 & 56 & & \\
\hline & tRNA & 23 & 17 & 18 & 18 & 17 & 18 & 35 & & \\
\hline & rRNA & 3 & 3 & 3 & 3 & 3 & 3 & 4 & & \\
\hline & total & 59 & 55 & 55 & 54 & 53 & 54 & 95 & & \\
\hline & $\%$ & 16.48 & 17.45 & 17.34 & 17.35 & 15.82 & 17.35 & 17.68 & & \\
\hline \multirow[t]{2}{*}{ ORF } & ORFs & 40 & 46 & 45 & 44 & 36 & 44 & 44 & & \\
\hline & que region (\%) & 8.60 & 0.74 & 0.28 & 0 & 1.57 & 0 & 0 & & \\
\hline \multicolumn{2}{|c|}{ cp-derived sequences (\%) } & 2.88 & 3.36 & 3.33 & 3.39 & 3.21 & 3.39 & 3.53 & & \\
\hline \multirow{2}{*}{\multicolumn{2}{|c|}{ Large repeat (bp) }} & $\mathrm{R}^{\prime}$ & $\mathrm{R}$ & $\mathrm{R}$ & $\mathrm{R}$ & R3 & $\mathrm{R}$ & $\mathrm{R}$ & $\mathrm{R} 1$ & $\mathrm{R} 2$ \\
\hline & & 9713 & 2427 & 2427 & 2427 & 6580 & 2427 & 2427 & 141800 & 3605 \\
\hline \multicolumn{2}{|c|}{ Short repeat (\%) } & 6.54 & 7.13 & 6.57 & 6.34 & 6.29 & 8.70 & 5.31 & & \\
\hline
\end{tabular}

* Part of the data cited from $[15,17]$. 


\section{Competing interests}

The authors declare that they have no competing interests.

\section{Authors' contributions}

YW and RG conceived and designed the study. JW, JJ, AL participated in the experiments. JW, $\mathrm{XL}$ and $\mathrm{YZ}$ analyzed the data. All authors drafted the manuscript and approved the final manuscript.

\section{Acknowledgments}

This work was supported by the NSFC project $(30971812,31171581)$, a Project Funded by the Priority Academic Program Development of Jiangsu Higher Education Institutions, Program of International S \&T Cooperation of China (1021) and the project of Jiangsu Province (BRA2010141, CXLX11_0998).

\section{Author details}

${ }^{1}$ Jiangsu Provincial Key Laboratory of Crop Genetics and Physiology, Yangzhou University, Yangzhou 225009, China. ${ }^{2}$ Jiangsu Institute of Agricultural Science in the Lixiahe District, Yangzhou 225009, China. ${ }^{3}$ State Key Laboratory of Crop Genetics and Germplasm Enhancement, Nanjing Agricultural University, Nanjing 210095, China.

Received: 24 July 2012 Accepted: 27 November 2012

Published: 28 November 2012

\section{References}

1. Nathalie $P$, Michael $H$, Luigi $P$, Ferdinando $P$ : The growing family of mitochondrial carriers in Arabidopsis. Trends Plant Sci 2004, 9:138-146.

2. Oda K, Yamato K, Ohta E, Nakamura Y, Takemura M, Nozato N, Akashi K, Kanegae T, Ogura Y, Kohchi T: Gene organization deduced from the complete sequence of livewort Marchantia polymorpha mitochondrial DNA primitive form of plant mitochondrial genome. Mol Biol 1992, 223:1-7.

3. Gray MW, Lang BL, Cedergren R, Golding GB, Lemieux C, Sankoff D, Turmel M, Brossard N, Delage E, Littlejohn TG, et al: Genome structure and gene content in protist mitochondrial DNAs. Nucleic Acids Res 1998, 26:865-878

4. Unseld M, Marienfeld JR, Brandt $P$, Brandt $P$, Brennicke A: The complete genome of Arabidopsis thaliana contains 57 genes in 366,924 nucleotides. Nat Genet 1997, 15:57-61.

5. Notsu Y, Masood S, Nishikawa T, Kubo N, Akiduki G, Nakazono M, Hirai A Kadowaki K: The complete sequence of the rice (Oryza sativa L.) mitochondrial genome: frequent DNA sequence acquisition and loss during the evolution of flowering plants. Mol Genet Genomics 2002, 268:434-445.

6. Tian $X$, Zheng J, Hu S, Yu J: The rice mitochondrial genomes and their variations. Plant Physiol 2006, 140:401-410.

7. Fujii S, Kazama T, Yamada M, Toriyama K: Discovery of global genomic re-organization based on comparison of two newly sequenced rice mitochondrial genomes with cytoplasmic male sterility-related genes. BMC Genomics 2010, 11:209.

8. Satoh M, Kubo T, Nishizaw S, Estiati A, Itchoda N, Mikami T: The cytoplasmic male-sterile type and normal type mitochondrial genomes of sugar beet share the same complement of genes of known function but differ in the content of expressed ORFs. Mol Genet Genomics 2004, 272:247-256.

9. Kubo T, Nishizawa S, Sugawara A, Itchoda N, Estiati A, Mikami T: The complete nucleotide sequence of the mitochondrial genome of sugar beet (Beta vulgaris L.) reveals a novel gene for tRNA(Cys) (GCA). Nucleic Acids Res 2000, 28:2571-2576.

10. Clifton SW, Minx P, Fauron CM, Gibson M, Allen JO, Sun H, Thompson M Barbazuk WB, Kanuganti S, Tayloe C, et al: Sequence and comparative analysis of the maize NB mitochondrial genome. Plant Physiol 2004, 136:486-3503.

11. Allen JO, Fauron CM, Minx P, Roark L, Oddiraju S, Lin GN, Meyer L, Sun H, Kim K, Wang C, et al: Comparison among two fertile and three male-sterile mitochondrial genomes of maize. Genetics 2007, 177:1173-1192.

12. Sugiyama $Y$, Watase $Y$, Nagase M, Makita N, Yagura S, Hirai A, Sugiura M: The complete nucleotide sequence and multipartite organization of the tobacco mitochondrial genome: comparative analysis of mitochondrial genomes in higher plants. Mol Genet Genomics 2005, 272:603-615.

13. Ogihara Y, Yamazaki Y, Murai K, Kanno A, Terachi T, Shiina T, Miyashita N, Nasuda S, Nakamura C, Mori N, et al: Structural dynamics of cereal mitochondrial genomes as revealed by complete nucleotide sequencing of the wheat mitochondrial genome. Nucleic Acids Res 2005, 33:6235-6250

14. Liu HT, Cui P, Zhan KH, Qiang L, Zhuo GY, Guo XL, Ding F, Yang WL, Liu DC, et al: Comparative analysis of mitochondrial genomes between a wheat K-type cytoplasmic male sterility (CMS) line and its maintainer line. BMC Genomics 2011, 12:163.

15. Chen JM, Guan RZ, Chang SX, Du TQ, Zhang HS, Xing H: Substoichiometrically different mitotypes coexist in mitochondrial genomes of Brassica napus L. PLoS One 2011, 6:1-8.

16. Handa $H$ : The complete nucleotide sequence and RNA editing content of the mitochondrial genome of rapeseed (Brassica napus L.): comparative analysis of the mitochondrial genomes of rapeseed and Arabidopsis thaliana. Nucleic Acids Res 2003, 31:5907-5916

17. Chang S, Yang TT, Du TQ, Huang YQ, Chen JM, Yan LY, He LB, Guan RZ: Mitochondrial genome sequencing helps show the evolutionary mechanism of mitochondrial genome formation in Brassica. BMC Genomics 2011, 12:479.

18. Liu JH, Xu XY, Deng $X X$ : Intergeneric somatic hybridization and its application to crop genetic improvement. Plant Cell, Tiss Org Cult 2005, 82:19-44.

19. Yamagishi H, Glimelius K: Somatic hybrids between Arabidopsis thaliana and cytoplasmic male-sterile radish (Raphanus sativus). Plant Cell Rep 2003, 22:52-58.

20. Sakai T, Imamura J: Intergeneric transfer of cytoplasmic male sterility between Raphanus sativus (CMS line) and Brassica napus through cytoplast-protoplast fusion. Theor App/ Genet 1990, 80:421-427.

21. Jourdan PS, Earle ED, Mutschler MA: Synthesis of male sterile, triazine-resistant Brassica napus by somatic hybridization between cytoplasmic male sterile B. oleracea and atrazine-resistant B. campestris. Theor Appl Genet 1989, 78:445-455.

22. Pelletier G, Primard C, Vedel F, Chetrit P, Remy R, Rousselle, Renard M: Intergeneric cytoplasmic hybridization in cruciferae by protoplast fusion. Mol Gen Genet 1983, 191:244-250.

23. Bannerot H, Boulidard L, Cauderon Y, Tempe J: Transfer of cytoplasmic male sterility from Raphanus sativus to Brassica oleracea. Proc. Eucarpia Meet. Cruciferae 1974, 25:52-54.

24. Krishnasamy S, Makaroff CA: Characterization of the radish mitochondrial orfB locus: Possible relationship with male sterility in Ogura radish. Curr Genet 1993, 24:156-163.

25. Bonhomme S, Budar F, Lancelin D, Small I, Defrance MC, Pelletier G: Sequence and transcript analysis of the Nco2.5 Ogura-specific fragment correlated with cytoplasmic male sterility in Brassica cybrids. Mol Gen Genet 1992, 235:340-348.

26. Jing B, Heng S, Tong D, Wan Z, Fu T, Tu J, Ma C, Yi B, Wen J, Shen J: A male sterility-associated cytotoxic protein ORF288 in Brassica juncea caused aborted pollen development. J Exp Bot 2012, 63:1285-1295.

27. Dewey RE, Timothy DH, Levings CS: A mitochondrial protein associated with cytoplasmic male sterility in the T cytoplasm of maize. Proc Natl Acad Sci, USA 1987, 84:5374-5378

28. Wise RP, Pring DR, Gengenbach BG: Mutation to male fertility and toxin insensitivity in Texas (T)-cytoplasm maize is associated with a frameshift in a mitochondrial open reading frame. Proc Natl Acad Sci, USA 1987, 84:2858-2862

29. Wise RP, Broson CR, Schnable PS, Homer HT: The genetics, pathology, and molecular biology of T-cytoplasm male sterility in maize. Adv Agro 1999, 65:79-130.

30. Akagi H, Nakamura A, Yokozeki-Misono Y, Inagaki A, Takahashi H, Mori K, Fujimura T: Positional cloning of the rice Rf-1 gene, a restorer of BT-type cytoplasmic male sterility that encodes a mitochondria-targeting PPR protein. Theor Appl Genet 2004, 108:1449-1457.

31. Wang ZH, Zou Y, Li X, et al: Cytoplasmic male sterility of rice with boro II cytoplasm is caused by a cytotoxic peptide and is restored by two related $P P R$ motif genes via distinct modes of mRNA silencing. Plant Cell 2006, 18:676-687.

32. Palmer JD, Shields CR: Tripartite structure of the Brassica campestris mitochondrial genome. Nature 1984, 307:437-440. 
33. Satoh M, Nemoto Y, Kawano S, Nagata T, Hirokawa H, Kuroiwa T: Organization of heterogeneous mitochondrial DNA molecules in mitochondrial nuclei of cultured tobacco cells. Protoplasma 1993, 175:112-120.

34. Andre C, Levy A, Walbot V: Small repeated sequences and the structure of plant mitochondrial genomes. Trends Genet 1992, 8:128-132.

35. Oshima M, Kikuchi R, Imamura J, Handa H: Origin of the CMS gene locus in rapeseed cybrid mitochondria: active and inactive recombination produces the complex CMS gene region in the mitochondrial genomes of Brassicaceae. Genes Genet Syst 2010, 85:311-318.

36. Nakazono M, Nishiwaki S, Tsutsumi N: A chloroplast-derived sequence is utilized as a source of promoter sequences for the gene for subunit 9 of NADH dehydrogenase (nad9) in rice mitochondria. Mol Gen Genet 1996, 252:371-378.

37. Handa H, Bonnard HG, Grienenberger JM: The rapeseed mitochondrial gene encoding a homologue of the bacterial protein $\mathrm{Cc} 11$ is divided into independently transcribed reading frames. Mol Gen Genet 1996, 252:292-302.

38. Heazlewood JL, Whelan J, Millar AH: The products of the mitochondrial orf 25 and orfB genes are FO components in the plant F1FO ATP synthase. FEBS Lett 2003, 540:201-205.

39. Jing B, Heng S, Tong D, Wan Z, Fu T, Tu J, Ma C, Yi B, Wen J, Shen J: A male sterility-associated cytotoxic protein ORF288 in Brassica juncea causes aborted pollen development. J Exp Bot, 63:1285-1295.

40. Duroc Y, Gaillard C, Hiard S, Defrance MC, Pelletier G, Budar F: Biochemical and functional characterization of $O R F 138$, a mitochondrial protein responsible for Ogura cytoplasmic male sterility in Brassicaceae. Biochimie 2005, 87:1089-1100

41. Desloire S, Gherbi H, Laloui W, Marhadour S, Clouet V, Cattolico L, Falentin C, Giancola S, Renard M, Budar F, et al: Identification of the fertility restoration locus, $R f$, in radish, as a member of the pentatricopeptide-repeat protein family. EMBO Rep 2003, 4:588-594.

42. Giancola S, Marhadour S, Desloire S, Clouet V, Falentin-Guyomarc'h H, Laloui W, Falentin C, Pelletier G, Renard M, Bendahmane A, et al: Characterization of a radish introgression carrying the Ogura fertility restorer gene Rfo in rapeseed, using the Arabidopsis genome sequence and radish genetic mapping. Theor Appl Genet 2003, 107:1442-1451.

43. Uyttewaal M, Arnal N, Quadrado M, Martin-Canadell A, Vrielynck N, Hiard S, Gherbi H, Bendahmane A, Budar F, Mireau H: Characterization of Raphanus sativus pentatricopeptide repeat proteins encoded by the fertility restorer locus for ogura cytoplasmic male sterility. Plant Cell 2008, 20:3331-3345.

44. Schattner P, Brooks AN, Lowe TM: The tRNAscan-SE, snoscan and snoGPS wed servers for the detection of tRNAs and snoRNAs. Nucl Acids Res 2005, 33:W686-W689.

45. Schwartz S, Zhang Z, Frazer KA, Smit A, Riemer C, Bouck J, Gibbs R, Hardison R, Miller W: PipMaker-a web server for aligning two genomic DNA sequences. Genome Res 2000, 10:577-586.

doi:10.1186/1471-2164-13-675

Cite this article as: Wang et al: Complete sequence of heterogenouscomposition mitochondrial genome (Brassica napus) and its exogenous source. BMC Genomics 2012 13:675.

\section{Submit your next manuscript to BioMed Central and take full advantage of:}

- Convenient online submission

- Thorough peer review

- No space constraints or color figure charges

- Immediate publication on acceptance

- Inclusion in PubMed, CAS, Scopus and Google Scholar

- Research which is freely available for redistribution 